\title{
TRABALHO PRECARIZADO NA PANDEMIA E OS OBJETIVOS DE DESENVOLVIMENTO SUSTENTÁVEL
}

\author{
Andrea Elena Pizarro Munoz* \\ Janilza Bezerra da Silva Morais** \\ Yeken Anwar Serri*** \\ Leonardo Soares Giordano****
}

RESUMO

A pandemia do novo coronavírus tem trazido uma série de mudanças para a sociedade que extrapolam a crise sanitária de proporções mundiais. A necessidade de isolamento social impôs a necessidade de trabalhar de casa para uma parcela da população que pôde recorrer a esta alternativa e com isso impulsionou o crescimento dos serviços prestados por aplicativos. Neste ensaio, abordamos as implicações do trabalho dos entregadores por aplicativo no âmbito do ODS 8 Crescimento econômico e trabalho decente. Do discurso de empreendedorismo, consumo consciente à falta de direitos trabalhistas e baixa remuneração, analisa-se o trabalho precarizado na pandemia à luz das transformações nas relações de trabalho no Brasil, o aprofundamento da crise econômica e desemprego, o processo de uberização e os impactos para trabalhadores e empresas de serviços por aplicativos. Ao final, são apontadas algumas iniciativas de reação dos trabalhadores em torno de movimentos de valorização do trabalhador e união por reivindicação de direitos.

Palavras-chave: Objetivos de Desenvolvimento Sustentável. Trabalho decente. Uberização. Entregadores. Precarização.

* http://orcid.org/0000-0001-7358-4500. Universidade Metodista de São Paulo. Economista graduada pela Universidade Estadual de Campinas (1998) e mestre em Desenvolvimento Econômico - Economia Regional e Urbana pela Universidade Estadual de Campinas (2008). Graduanda em jornalismo pela Universidade Metodista de São Paulo. Tem experiência na área de socioeconomia, atuando principalmente nos seguintes temas: desenvolvimento econômico, economia regional e urbana, políticas públicas, economia agrícola, aquicultura, avaliação de impactos sociais, econômicos e ambientais, sustentabilidade, viabilidade econômico-financeira, estudos de cadeia de valor. aemunoz00@gmail.com .

** Universidade Metodista de São Paulo. Contadora e graduanda em jornalismo pela Universidade Metodista de São Paulo. janilzabezerra@gmail.com .

***Universidade Metodista de São Paulo. Publicitário e graduando em jornalismo pela Universidade Metodista de São Paulo. yeken@onira.com.br.

**** Universidade Metodista de São Paulo. Graduando em jornalismo pela Universidade Metodista de São Paulo. leogiordano.educa@gmail.com . 


\section{INTRODUCÃO}

O momento de pandemia do novo coronavírus trouxe uma séria crise mundial, não somente por conta da doença e sua gravidade, que resultou em aumento de contaminações, mortes e incapacidade de atendimento pela rede pública de saúde. O isolamento social, seguido do fechamento do comercio, indústrias e atividades não essenciais, piorou muito o quadro. A temática dialoga com o ODS (objetivo de desenvolvimento sustentável) 8: Trabalho decente e crescimento econômico pela sua emergência dentre as preocupações da sociedade e por indicar que possivelmente as relações de trabalho irão mudar, adaptando-se aos novos tempos e com tendência à precarização. $\mathrm{O}$ home office, trabalho feito à distância veio para ficar em diversas atividades, outras terão que se reinventar para sobreviver e gerar empregos de qualidade, trabalho decente, que respeitem a integridade dos trabalhadores.

A crise sanitária aliada à crise econômica criou um cenário de "tempestade perfeita" em muitos países, e no Brasil, aliada à reforma trabalhista que suprimiu muitos dos direitos dos trabalhadores, aprofundou a informalidade e desemprego e consequentemente o desamparo. Diante das perspectivas de sucesso cada vez mais distantes, muitos acabam desistindo de procurar emprego, amplificando o desemprego por desalento. O perfil de contratação mudou também, a "uberização" dos trabalhadores é uma realidade preocupante, sem estabilidade, registro, e outras garantias deixam o trabalhador à míngua e sujeito à baixa remuneração. É assim com empresas de entregas, de compras terceirizadas como o Rappi, de fornecimento de refeições como o IFOOD, UBER EATS e outras que passaram a terceirizar sua atividade, algo antes proibido.

Neste ensaio serão abordados: como o trabalho de entregas tem crescido, quais são os principais segmentos e empresas envolvidos, quem são estes trabalhadores e como é sua luta diária por direitos básicos. A análise ocorrerá no âmbito da Agenda 2030 da ONU, especificamente em relação ao objetivo para o desenvolvimento sustentável número 8: trabalho decente e crescimento econômico.

\section{DESENVOLVIMENTO SUSTENTÁVEL, CRESCIMENTO ECONÔMICO E TRABALHO}

A Agenda 2030, adotada na Assembleia Geral da ONU em 2015, é um plano de ação que representa uma continuidade da discussão dos objetivos do milênio estabelecidos na década de 1990 e sintetiza as mais importantes 
ambições das sociedades humanas para esta década. Indica 17 Objetivos de Desenvolvimento Sustentável, os ODS, e 169 metas, para erradicar a pobreza e promover vida digna para todos, dentro dos limites do planeta, a serem atingidos até 2030. Está alicerçado no relatório Nosso Futuro Comum (1987), que institui a seguinte definição de desenvolvimento sustentável: “O desenvolvimento que procura satisfazer as necessidades da geração atual, sem comprometer a capacidade das gerações futuras de satisfazerem as suas próprias necessidades."

O objetivo 8 consiste em "Promover o crescimento econômico sustentado, inclusivo e sustentável, o emprego pleno e produtivo e o trabalho decente para todos". Como premissa, estabelece que, no longo prazo, a desigualdade de renda e de oportunidades prejudica o crescimento econômico e o alcance do desenvolvimento sustentável. Isto se deve ao fato de que os mais vulneráveis, muitas vezes, têm menor expectativa de vida e apresentam dificuldades de se libertarem de um círculo vicioso de insucesso escolar, baixas qualificações e poucas perspectivas de empregos de qualidade.

Das 10 metas estabelecidas para este objetivo, o presente ensaio discute aspectos relacionados à meta 8.8: Proteger os direitos trabalhistas e promover ambientes de trabalho seguros e protegidos para todos os trabalhadores, incluindo os trabalhadores migrantes, em particular as mulheres migrantes, e pessoas em empregos precários. ${ }^{2}$

\section{MODERNIDADE E ATRASO NAS RELACÕES DE TRABALHO}

Resulta paradoxal que no capitalismo do século XXI, em plena era da tecnologia informacional digital, indústria 4.0, quando se imaginava que os trabalhadores teriam mais liberdade, ocorra justamente a situação inversa. Observa-se o convívio de tecnologias cada vez mais avançadas com práticas pretéritas de exploração do trabalho, como ausência de direitos trabalhistas e jornadas de trabalho extenuantes, semelhantes àquelas vividas pelos trabalhadores em Manchester, Inglaterra, no florescimento da primeira revolução industrial no século XVIII.

Inicialmente, quando foi implementada a nova forma de trabalho em plataformas globais, especificamente de caronas, tratou-se de associá-las ao tema emergente da economia compartilhada e à preocupação com consumo

http://www.agenda2030.org.br/sobre/

https://odsbrasil.gov.br/objetivo/objetivo? $\mathrm{n}=8$ 
consciente, afinal parecia uma ótima ideia para o usuário poder contar com um serviço de transporte individual a um custo mais acessível que o táxi, fazendo com que muitas pessoas abrissem mão de possuir um automóvel e com este todas as despesas que o acompanham, como licenciamento, estacionamento, manutenção e até eventuais multas de trânsito. Por outro lado, para o motorista as tarifas recebidas eram inicialmente atraentes e o discurso de empreendedorismo, de autonomia para decidir sobre a própria jornada de trabalho conforme sua conveniência, gerando renda complementar ou exclusiva também soava sedutor. Segundo a visão liberal, o mercado regula melhor as relações de trabalho, desta forma a tecnologia dos aplicativos e algoritmos propiciaria o encontro entre ofertantes e demandantes de determinados serviços de forma ágil, fácil e trazendo benefícios e incremento de bem-estar à sociedade como um todo.

Entretanto, aos poucos foram se revelando novas facetas deste novo processo conhecido como "uberização", uma derivação do nome da plataforma de transportes Uber, como um processo no qual as relações de trabalho são cada vez mais individualizadas e invisibilizadas, sendo o assalariamento e a exploração cada vez mais encobertos pela insegurança e falta de redes convencionais de proteção, transferência de custos e riscos para o trabalhador. O termo "indústria 4.0" aponta para a ampliação dos processos produtivos cada vez mais automatizados e robotizados em toda a cadeia de valor controlada digitalmente, destruindo a separação entre o tempo de vida dentro e fora dele, originando uma "escravidão digital” (ANTUNES, 2020).

Na linguagem técnica, algoritmo é uma sequência finita de instruções ou operações executado para resolver um problema computacional. No caso dos aplicativos de transporte, é uma ferramenta que reúne todas as informações disponibilizadas pelo motorista e pelo passageiro e, a partir delas, define preços e trajetos, prioriza um trabalhador em detrimento de outro, estabelece punições e recompensas (BRASIL DE FATO, 2021).

Esta é uma tendência em curso implementada por corporações globais e que se intensificou com o advento da pandemia de SARS CoV-2. Facilitada pelas Tecnologias da Informação e Comunicação (TIC), a expansão dos aplicativos desenvolve e amplia de modo exponencial o infoproletariado ou ciberproletariado em uma variada gama de serviços, inclusive de entregas ou "delivery" (adaptado de ANTUNES \& BRAGA 2009).

Uma das recentes inovações relacionadas a plataformas de caronas é a possibilidade de negociar o preço com os motoristas, como ocorre por 
meio do InDriver, um aplicativo de transporte colaborativo, concorrente ao Uber e à 99. O diferencial dessa plataforma: ao solicitar cada viagem, o usuário sugere o valor que deseja pagar. Em seguida, são mostrados os preços cobrados pelos motoristas disponíveis, com opções de aceitar ou recusar a viagem. A estimativa também leva em consideração a demanda de pedidos no momento. (MAGALHÃES, 2021)

\section{EM BUSCA DE MELHORES CONDIÇÕES DE VIDA}

O delivery também foi um forte aliado durante esse período de pandemia, tanto para aqueles que estavam isolados em casa, quanto para muitas empresas que puderam continuar operando, tornando-se uma fonte de renda para estes estabelecimentos e também para os entregadores.

Com a alta demanda, as principais empresas do setor de entregas ampliaram a quantidade de entregadores nas ruas, acirrando assim ainda mais a disputa por corridas.

Com um número cada vez maior de entregadores no período de isolamento social, evidenciou-se a precarização das condições de trabalhado da categoria no país. Os entregadores são vistos por essas empresas como empreendedores autônomos, desta forma as plataformas digitais se isentam de responsabilidades e custos trabalhistas.

O trabalho deve ser fator de dignidade e de valorização do ser humano em todos os aspectos de sua vida, sejam eles profissionais ou pessoais. Razão pela qual, denota-se o trabalho decente como um direito humano e fundamental do trabalhador por assegurar-lhe ou garantir-lhe o acesso aos bens materiais, ao bem estar, à satisfação profissional e ao completo desenvolvimento de suas potencialidades e de sua realização pessoal, bem como o direito à sua integração social.

(ALVARENGA, Rúbia Zanotelli, Trabalho Decente - Direito Humano e Fundamental. $2^{\circ}$ Edição, Editora Dialética, 2020).

Não existe um número exato de quantos entregadores estão em atividade no país, mas dados levantados pela consultoria Análise Econômica mostram que, do total de trabalhadores informais no Brasil, os que prestam serviço para aplicativos de entrega de refeições saltaram de 250.000 pessoas em 2019 para mais de 645.000 em junho de 2020. Um crescimento de, aproximadamente, 158\% (COLAVIT'TI, 2020) 


\section{EXPANSÃO DO TRABALHO PRECARIZADO NO BRASIL}

No Brasil, o caminho para a expansão das novas formas de trabalho precarizado foi pavimentado com a reforma trabalhista ocorrida em 2017 com a flexibilização da consolidação das leis do trabalho (CLT) e ampliação da terceirização de atividades, implementação de trabalho intermitente; a mudança de regras de acesso à previdência social em 2019 e em 2020 com a complementação à reforma de 2017. Conforme LUCI PRAU (in ANTUNES ET AL, 2020), tais reformas forneceram legalidade e segurança jurídica ao capital e não ao trabalhador, com a justificativa de que trariam mudanças necessárias para a geração de novos empregos e retomada do crescimento econômico.

Entretanto, nenhum dos dois objetivos foi alcançado e a crise econômica que se acentuava antes mesmo da pandemia gerou uma imensa massa sobrante de trabalhadores desesperados que se sujeitam a qualquer remuneração, mesmo sem nenhuma garantia trabalhista. A expansão do trabalho precarizado atinge com mais força os jovens residentes nas periferias dos grandes centros urbanos, mas também a classe média com formação qualificada, que não encontra emprego no mercado formal.

"A Situação do mercado de trabalho revela muito sobre a economia do país, estado ou município. Ao observar o nível de empregos oferecidos e desemprego é possível saber se a economia está em período de retração ou desenvolvimento. Ao olhar para a economia do Brasil, temos um bom exemplo. Até o ano de 2013 a economia brasileira apresentou sinais de desenvolvimento, os índices de empregos formais estavam elevados e o terceiro setor era um dos que mais estava em expansão. A partir do ano de 2014, com os sinais de retração econômica o mercado de trabalho foi fortemente abalado, de forma que os índices de desemprego aumentaram de forma abrupta. Quando paramos para analisar estes fatores, é possível que entendamos muito o impacto social do mercado de trabalho em nosso dia-a-dia."

(KOEHLER, Fernanda dos Santos.; POFFO, Gabriella Depiné. Mercado de Trabalho e Carreira. Caderno de Estudos Ed.Avantis Digital, 2019, 51 p. )

Na pandemia, a situação se agravou, como mostra o aumento da taxa de desemprego para 14,2\% em janeiro de 2021, (figura 1) segundo o IBGE, ou cerca de 14 milhões de trabalhadores desempregados, além de 5,9 milhões de desalentados (que desistiram de buscar ocupação) e taxa de informalidade de $39,7 \%$ (sobre a população ocupada). 
Como ilustração da precarização, os entregadores precisam adquirir seus instrumentos de trabalho, como a mochila (bag), jaqueta, máquina de cartão, além, é claro, da motocicleta ou bicicleta. O maior número de motofretistas disponíveis faz com que o preço pago pelos fretes seja menor. Segundo pesquisa da Aliança Bike, um entregador que utilizava bicicleta e trabalhava mais de 12 horas diárias auferia rendimento mensal médio de $\mathrm{R} \$ 995$ em 2019.

\section{Taxa de desemprego}

Nos trimestres móveis até janeiro - em \%

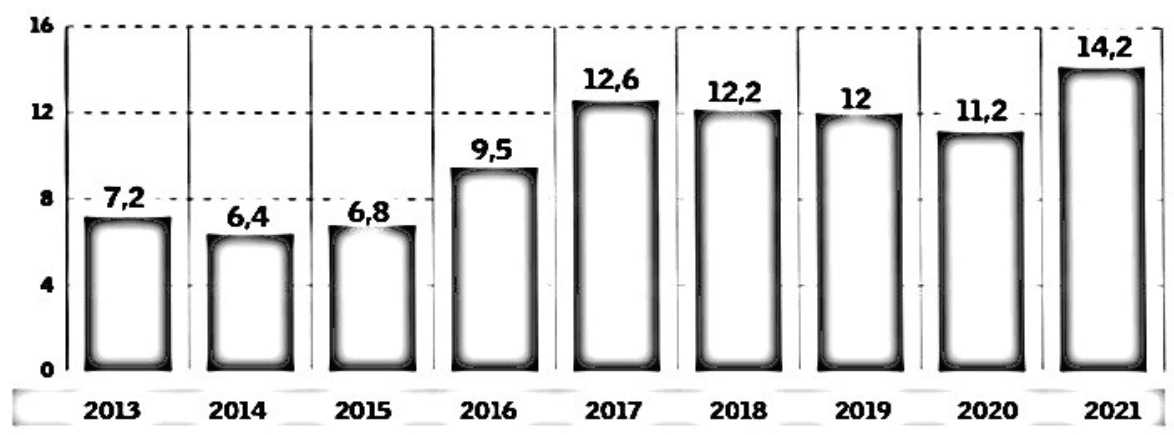

\section{Taxa de subutilização}

\% da população ocupada, nos trimestres móveis até janeiro

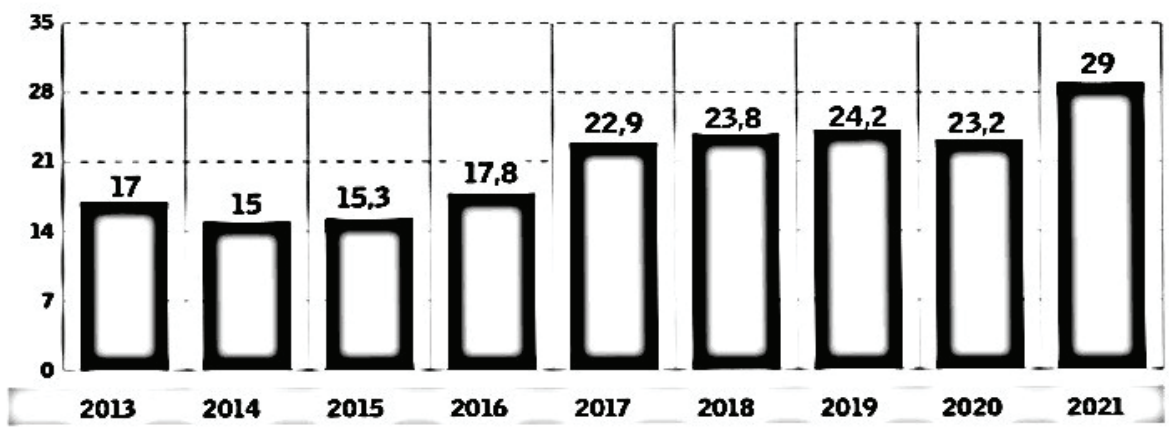

Fonte: Pnad Cont inua/18GE

Figura 1 - Taxa de desemprego e taxa de subutilização em trimestres móveis até janeiro de 2021

Um impacto ainda não mencionado do processo de uberizacao diz respeito à saúde mental dos trabalhadores, pois segundo Antunes a diluição das relações de solidariedade no trabalho aumentam a carga de sofrimento dos indivíduos: 
"Isso gera impacto no aumento dos adoecimentos psíquicos e sua expressão mais contundente é o suicídio, como uma manifestação mais radicalizada da deterioração das condições de trabalho sob a vigência da gestão flexível." (ANTUNES \& PRAUN, 2015).

Do lado do capital, entretanto, os resultados são positivos. Em 2019 o segmento de delivery movimentou $\mathrm{R} \$ 17$ bilhões, segundo O Globo, dado mostrado no programa Greg News (2020).

Segundo o Jornal Estadão, o IFood registrou 44,6 milhões de pedidos em agosto de 2020, um crescimento de cerca de $45 \%$ em relação aos pedidos feitos em março do mesmo ano. Durante o mesmo período, a empresa viu também o número de restaurantes parceiros aumentarem, hoje a empresa conta com cerca de $20 \%$ de todos os estabelecimentos do país.

Levantamento da Statista - empresa especializada em dados de mercado e consumidores - mostra o Brasil como destaque no segmento de delivery na América Latina em 2020. O País foi responsável por quase metade dos números do delivery, 48,77\%. Em seguida estão México e Argentina, com $27,07 \%$ e 11,85\%, respectivamente (JUNIOR, 2021).

\section{CONSIDERACÕES FINAIS}

Para resgatar a ideia inicial proposta para a elaboração do ensaio, alude-se à mensagem do Stockolm Resilience Center (apud ABRAMOVAY, 2021):

"A economia não é uma esfera autônoma da vida social. Ao contrário, ela está incrustada na política, na cultura, nos hábitos e na maneira como nos relacionamos uns com os outros. Uma sociedade sem paz, justiça e instituições fortes não será economicamente forte. Mais do que isso: se é verdade que o ODS 8 preconiza crescimento econômico, essa meta está ligada ao que a OIT (Organização Internacional do Trabalho) define como trabalho decente".

Conforme visto ao longo do ensaio, a assimetria de forças entre o capital e o trabalho é evidente porém não constitui processo inexorável e sim sujeito a constantes disputas na assimilação desta narrativa. As jornadas extenuantes de trabalho não são um limite para a organização coletiva dos trabalhadores das plataformas digitais. Ao longo dos últimos anos, surgiram associações, sindicatos e novas formas de organização nas mais diferentes categorias - do setor de tecnologia ao de games passando pelos youtubers. E o mesmo acontece 
com os entregadores em muitos países. Asociación de Personal de Plataformas (APP), na Argentina, Independent Workers' Union of Great Britain (IWGB), na Inglaterra, e \#NiUnRepartidorMenos, do México, são alguns exemplos de como os trabalhadores estão se organizando. No Brasil, só entre os motoristas, já há, no mínimo, 18 sindicatos e associações, algo que também vem emergindo em relação aos entregadores.(GROHMAN E ALVES, 2020)

As disputas pela "inovação" movem-se para o campo político e de marcos regulatórios legais que possuem um centro de gravidade ainda desfavorável às demandas e às exigências dos trabalhadores. Se o trabalho em plataformas é um laboratório de lutas de classes, é preciso testá-lo nas lutas em torno da classe trabalhadora. Nesses momentos de intensa solidariedade, de organização coletiva, o trabalhador se enxerga como trabalhador, assim como os demais trabalhadores, contra a injustiça e a exploração. Como costuma dizer Paulo Lima - o Galo - dos Entregadores Antifascistas, todo mundo é entregador "se você entrega a sua força de trabalho, você é um entregador".

As manifestações popularizadas como Breque dos Apps ocorridas em julho de 2020 serviram para mostrar o quanto a desigualdade está presente no dia a dia destes trabalhadores, e como a união em torno do objetivo comum tem o poder de reivindicar melhores condições de trabalho, garantia de uma remuneração justa e condições dignas de saúde e segurança para todos.

\section{REFERÊNCIAS}

ABRAMOVAY, R. Um 'bolo de noiva' para celebrar a Semana do Meio Ambiente. Blog. Disponível em: https://publicador.uolinc.com/media.jsp?contentUri=/br/com $/ \mathrm{uol} / \mathrm{tab} / \mathrm{colunas} / \mathrm{ricardo-}$ -abramovay/2021/06/02/um-bolo-de-noiva-para-a-semana-do-meio-ambiente.xml Acesso em 5 jun 2021.

ALVARENGA, Rúbia Zanotelli, Trabalho Decente - Direito Humano e Fundamental. $2^{\circ}$ Edição, Editora Dialética, 2020.

ANTUNES, Ricardo (org.). Uberização, trabalho digital e indústria 4.0. 1. ed. São Paulo: Boitempo, 2020. 333 pp.

ANTUNES, R., \& PRAUN, L. (2015). A sociedade dos adoecimentos no trabalho. Serv. Soc. Soc., São Paulo, 123, 407-427.

ANTUNES, Ricardo \& BRAGA, Ruy (orgs). Infoproletrários: degradação real do trabalho virtual. São Paulo: Boitempo, 2009.

ASSOCIAÇÃO BRASILEIRA DO SETOR DE BICICLETAS - Aliança Bike. Pesquisa de Perfil dos Entregadores ciclistas de aplicativo. São Paulo. 2019. Disponível em: https://aliancabike.org.br/wp-content/uploads/2020/04/relatorio_s2.pdf Acesso em 30 abr de 2021.

BRASIL DE FATO. Primeiro motorista a processar a Uber no Brasil: “O algoritmo é o novo capataz”. 30 de abril de 2021. Disponível em: https://www.brasildefato.com.br/2021/04/30/primeiro-motorista-a-processar-a-uber-no-brasil-o-algoritmo-e-o-novo-capataz. Acesso em 1 mai. 2021. 
COLAVITTI, Fernanda. Trabalhar mais por menos: a dura realidade de entregadores dos aplicativos. Revista VC S/A, 2020. 21 de agosto de 2020. Disponível em: https://vocesa.abril.com.br/carreira/ trabalhar-mais-por-menos-a-dura-realidade-de-entregadores-dos-aplicativos/ Acesso em 5 mai. 2021.

FOLHA DE SÃO PAULO/TV FOLHA - 'Entregador Antifascista' critica precarização do trabalho e omissão de veículos da imprensa - videoentrevista com Paulo Galo, primeiro episódio da série "E eu?" de 21 de fevereiro de 2021. Disponível em: https://www.youtube.com/watch?v=ttciccleoIg. Acesso em 30 mar. 2021.

GREG NEWS - Delivery. $4^{\circ}$ episódio da $4^{a}$ temporada do Greg News, com Gregorio Duvivier em 20 de abril de 2020. Programa produzido pelo canal HBO e distribuído no Youtube. Disponível em https:// www.youtube.com $/$ watch? $=\mathrm{v} 3 \mathrm{~B} 9 \mathrm{w} 6 \mathrm{wWNQA} \& \mathrm{t}=5 \mathrm{~s}$

Acesso em 15 abr 2021.

GROHMAN, R. \& ALVES, P. Quando os entregadores se fazem classe. Jacobin Brasil. Julho de 2020. Disponível em: https://jacobin.com.br/2020/07/quando-os-entregadores-se-fazem-classe/ acesso em 1 jun 2021.

JUNIOR, France. Delivery transformou tendência em necessidade e continua em crescimento. Jornal USP, 10 de março de 2021. Disponível em: https://jornal.usp.br/atualidades/delivery-transformou-tendencia-em-necessidade-e-continua-em-crescimento/ Acesso em 1 mai 2021.

INSTITUTO BRASILEIRO DE GEOGRAFIA E ESTATÍ́STICA - IBGE. Pesquisa Nacional por Amostra de Domicílios Contínua - PNAD Contínua. Taxa de desemprego. Taxa de ocupação. Mar de 2021. Disponível em:https://www.ibge.gov.br/estatisticas/sociais/trabalho/9171-pesquisa-nacional-por-amostra-de-domicilios-continua-mensal.html?edicao=30387\&t=destaques Acesso em 25 mar 2021.

KOEHLER, Fernanda dos Santos.; POFFO, Gabriella Depiné. Mercado de Trabalho e Carreira. Caderno de Estudos Ed.Avantis Digital, 2019.

ORGANIZAÇÃO DAS NAÇÕES UNIDAS (ONU). Plataforma Agenda 2030. Disponível em http:// www.agenda2030.org.br/sobre/ Acesso em 10 abr de 2021.

ORGANIZAÇÃO DAS NAÇÕES UNIDAS (ONU). Objetivo 8 - Emprego Decente e Crescimento Econômico. Disponível em: https://odsbrasil.gov.br/objetivo/objetivo?n=8. Acesso em 12 abr. 2021.

MAGALHÃES, A. Como funciona o app InDriver. Canaltech.4 de maio de 2021.Disponível em: https:// canaltech.com.br/apps/como-funciona-indriver/Acesso em 10 jun 2021.

PRAUN, L \& ANTUNES, R. A demolição dos direitos do trabalho na era do capitalismo informacional-digital in Uberização, trabalho digital e indústria 4.0. 1. ed. São Paulo: Boitempo, 2020.

TIMBÓ, N. V. Manual de referências para trabalhos acadêmicos: segundo ABNT NBR 6023 ago. 2002. Disponível em: https://metodista.br/biblioteca/arquivos/2020-manual-de-referencias_compressed. pdf. Acesso em: 15 abr. 2021.

O ESTADO DE SÃO PAULO. iFood cresce $50 \%$ em pedidos desde março e chega a 44,6 milhões de pedidos. Outubro de 2020. Disponível em https://link.estadao.com.br/noticias/inovacao,ifood-pedidos-45-milhoes-quarentena,70003468959 Acesso em 2 mai. 2021. 